\title{
I can't move or speak but I can hear and feel
}

\author{
Brian Boyle describes how communication with patients who have reduced consciousness can be \\ reassuring and motivating for their recovery
}

\section{Brian Boyle}

One month after graduating from high school I was in a near fatal car crash. My heart shifted across my chest, my lungs collapsed, and major organs were either lacerated or so badly injured they stopped functioning. My pelvis was shattered, and I lost $60 \%$ of my blood. I was airlifted to hospital near death and underwent immediate surgery-14 lifesaving procedures in total. On life support and in a critical condition, I was then placed in a medically induced coma for two months.

\section{Communicating beyond words}

I woke up in hospital with no memory of what had happened, so I depended on people around me to communicate what was taking place. My favourite care providers spoke to me as a person rather than just a comatose patient.

Good communication was verbal and non-verbal. I was somewhat conscious of my surroundings during the second half of the coma, and whenever someone walked into my room I was instantly attuned to their presence, mood, actions, energy (both positive and negative), and voice. They helped reorient me, prepared me for the next challenge, and mentioned things that made a connection with me as a person and motivated me to continue the recovery process. I craved interaction because it helped to momentarily distract me from my situation. A sense of trust developed each time I saw my care providers-even at times when my visual field was restricted to the ceiling or a wall, I could instantly sense their uplifting energy.

Clinicians, each time you leave a room and enter another, try to re-ground your thoughts and focus on centring your positive energy and attending to the needs of the next patient. Compartmentalise your thoughts, emotions, and experiences from those of the previous room.

\section{Get the patient's family working with you}

In most cases, family members have an incredible workload just trying to take care of the patient. One of my healthcare providers suggested that my parents designate a family spokesperson to share news and updates on my status, which was helpful because it kept my parents from having to constantly explain to friends and family the often agonising details of my condition. Having my relatives step in to the role of messenger helped my parents to stay energised and be able to spend more time with me.

Listen to feedback from the people who know the patient best-parents, family, partners, and close friends-because they may notice a small vital detail that the care providers have not. One day my parents saw something wasn't right with my behaviour towards the trache and my breathing pattern. They relayed their concern to the healthcare team. The first team member tried to reassure them that it was OK., but their parental instinct was on high alert and they went to talk to another member of the team. Within minutes the trache was removed as an emergency because it had become clogged. My parents' instinct saved my life.

Getting better was my internal battle, but the care provider played an important part in that battle. Victory was measured in the smallest increments, such as blinking or moving a finger, but, most importantly, victory was achieved through the compassionate work of my care providers. They believed in me when I didn't have the strength to believe in myself.

What you need to know

Even in a locked-in state, patients will rely heavily on cues from your actions and positive mood as well as your words

- Work with family members: suggesting ways they can support each other means they will be better able to support the patient

- Families and friends are in a position to spot problems you might miss: if they say the patient is deteriorating, take it seriously 


\section{Education into practice}

- How do you typically communicate with patients with reduced consciousness (for any reason)? What verbal or non-verbal cues could you use to communicate empathy with them?

- How do you typically prepare and support immediate family members for their role in caring for a critically ill relative and supporting or working with a wider network of support?

- How do you support carers or family members to feel confident about contributing their observations on progress and setbacks when caring for a critically ill patient?

- Is there anything else you might consider doing differently as a result of reading this article?

These questions were developed by the editors and reviewed by the patient author
Competing interests: The authors have read and understood BMJ policy on declaration of interests and declare the following: None.

Provenance and peer review: Commissioned, based on an idea from the author; not externally peer reviewed.

To hear Brian talking about his experiences: https://youtu.be/9-f6CDHDgzE and https://youtu.be/tuY4y1MQrhA

Published by the BMJ Publishing Group Limited. For permission to use (where not already granted under a licence) please go to http://group.bmj.com/group/rights-licensing/ permissions 